\title{
Biomechanics Analysis of Arm Flexion Isometric Force, Upper Extremity Movement, and Ball Toss Position Towards Ball Speed in Tennis Flat Serve
}

\author{
Setiyo Hartoto ${ }^{1, *}$ Muchamad Arif Al Ardha ${ }^{2}$, Awang Firmansyah ${ }^{3,}$ Bayu Budi \\ Prakoso $^{4,}$ Satwika Arya Pratama ${ }^{5}$ Panji Bana ${ }^{6}$ \\ ${ }^{1,2,4}$ Department of Physical Education, Universitas Negeri Surabaya, Indonesia \\ 3,6 Department of Sports Science, Universitas Negeri Surabaya, Indonesia \\ ${ }^{5}$ Department of Nutrition, Universitas Negeri Surabaya, Indonesia \\ *Corresponding author. Email: setiyohartoto@unesa.ac.id
}

\begin{abstract}
This study analyzed arm flexion isometric force, upper extremity movement, and ball toss position toward ball speed in tennis flat serve. Nine tennis players aged $20.78 \pm 5.044$ years old participated in this study and were chosen as research samples by using the purposive sampling method. The independent variables of this study were arm flexion isometric force, upper extremity movement, and ball toss position. The kinetic data were collected by Force Decks by Vald Performance, and kinematic data were analyzed by Kinovea 0.9 .4 computer software. The dependent variable was ball speed which was measured after the impact with racket by using Bushnell Velocity Speed Gun type 101911. The data were analyzed by using descriptive analysis and Kolmogorov-Smirnov normality test in SPSS statistical software. Furthermore, multiple linear regression was performed to find the correlation between variables. As a result, all of the data were in the normal distribution. The kinetic data were analyzed by using the descriptive method. The mean of arm flexion isometric peak force was $131.22 \pm 41.27$ Newton, arm flexion isometric average force was $121.44 \pm 42.08$ Newton, and rate force development was $270.33 \pm 112.88$ milliseconds. The kinematic data were also analyzed by using the descriptive method. The mean arm flexion and ball height in ball release position were $120.39 \pm 14.65^{\circ}$ and 165.76 $\pm 25.39 \mathrm{~cm}$. The mean peak ball position was $337.08 \pm 23.92 \mathrm{~cm}$. At the ball impact position, the mean of the hip torso, arm flexion isometric, and ball height were $30.46 \pm 15.42^{\circ}, 186.93 \pm 14.43^{\circ}$, and $258.77 \pm 26.51 \mathrm{~cm}$. The mean ball speed was $80.23 \pm 16.38 \mathrm{~km} / \mathrm{h}$. There was a significant correlation between ball height in peak position and impact position (R Score > .666). Furthermore, kinematic had a significant correlation with ball speed (R Score > .666).
\end{abstract}

Keywords: Flat serve, Kinetic analysis, Kinematic analysis.

\section{INTRODUCTION}

Tennis is a popular sport in society. This sport is not only played by adults but also children to teenagers. The ease of playing supported by adequate facilities and facilities makes many people interested in this sport. However, it requires extensive energy expenditure and endurance [1]. A tennis champion requires biomotor components and physiological. The biomotor component required by tennis is strength power, flexibility [2].

Furthermore, the involvement of biomechanics analysts could provide the analysis to improve the biomotor capability [3]. Besides, tennis also requires endurance and coordination. Persistence is essential because in tennis possible to play morning until night.
Last but not least, anthropometry is one of the critical success factors because athlete tennis needs height and arm span to serve or volley.

In addition to the biomotor components for tennis is very necessary, good techniques will support athletes to become champions. There are several techniques in playing tennis, such as service, backhand, and forehand [4]. Each of these techniques has its style. For example, service is divided into three types: flat serve, slice serve, and American serve. The main goal in service is to use power, swing, and placement to create a tennis weapon [4]. Currently, service is a start to the game and an attack aimed at scoring points. 
Furthermore, an excellent service requires strength, speed, accuracy, and good technique [5]. To serve well, a good pace, spin, and placement are needed [2]. The components of the kinetic chain follow stance, knee bend, hip rotation, trunk rotation, arm rotation, elbow extension and forearm pronation, wrist movement, and follow-through and landing [4].

One of these skills, service performance, results from the effective transfer of torque production that depends on technique, muscle strength, and flexibility [7]. Someone who has good serve ability has the principal capital to become a professional athlete. Serving, in particular, is the most demanding stroke in tennis, with supraphysiologic forces through the shoulder and elbow [8]. When the player serves, it will be an open kinetic chain. This kinetic chain begins at the feet and knees, progressing to the core and trunk, the shoulder and elbow, and finally to the wrist, hand, and racquet [9]. Through hundreds of strokes per match, the kinetic chain enables a player to generate high racquet and ball velocities while minimizing joint loads, especially with power shots including overhead serves, overhead smashes, and groundstrokes [6].

Flat services were influenced by upper and lower extremity muscle [10]. On the upper extremity of the contracting muscles is internal rotators. Elliot has stressed the vital role of internal rotation of the upper arm at the shoulder during service and forehand strokes [11]. It has been shown that the internal rotators of the dominants shoulder in tennis players produce greater torque than those who don't play tennis [12]. Furthermore, rotation sequence on the upper extremity is a substantial factor [13]. While in lower extremity muscles that contract is leg. Muscular force, which allows for explosive movements, and muscular endurance, which sustains a player through long matches, are essential components for tennis success [2]. Both the upper and lower extremities have each function that supports each other so that the flat service is optimal.

An athlete who performs multiple services in one training session has a potential risk of injury. For every 1000 hours an athlete is on the court practicing or competing, he will likely incur 2 to 20 damages [2]. This equates to 0.002 to 0.02 percent of playing time resulting in injury [14]. This can be due to improper techniques and limited specific muscle training used at the time of service [15]. The injuries were also caused by historical training methods [16]. One of the most common injuries in tennis athletes is upper body $26-31 \%$, body core 16 $20 \%$, lower body $39-51 \%$ [2]. These injuries are common in both recreational and professional tennis athletes. Therefore, to minimize injuries and improve excellent performance, it is necessary to emphasize doing the correct service - one of the services that can be done using the flat service technique. The advantage of flat service is easy to learn and can be presented immediately on beginner tennis.

Here, researchers will discuss how to perform an effective flat serve to minimize injury risk and gradually improve performance with biomechanical analysis. This research evaluates the correlation between arm, trunk, and legs kinematic position toward Ball Speed in Tennis Flat Serve.

\section{METHODS}

\subsection{Design and Sample}

This study was conducted in a correlational design with a quantitative approach. Universitas Negeri Surabaya Ethics Committee approved the research design. The independent variables of this study were arm flexion isometric force, upper extremity movement, and ball toss position. The dependent variable was ball speed which was measured after the impact with the racket. Nine tennis players aged $20.78 \pm 5.044$ years old participated in this study and were chosen as research samples by using the purposive sample method. The criteria of research samples were minimum of 10 years of tennis experience and still being active as a tennis player. Those research samples have filled informed concern to be part of this study. Each piece took a 5 serves trial before doing the test, and ten serves in the test. The legal serve (ball drop in to help zone) with the fastest speed was selected from every sample to be analyzed further.

\subsection{Data Collection}

The kinetic data were collected by Force Decks by Vlad Performance. It measured the arm flexion isometric force (Figure 1). The data which were collected by using this method were arm flexion isometric peak force (Newton), arm flexion isometric average force (Newton), and rate force development or also known as RFD (millisecond). The kinematic data were collected using kinematic video analysis in Kinovea 0.9.4 computer software (Figure 2). The data which were measured by the kinematic analysis were upper extremity movement and ball toss position. 


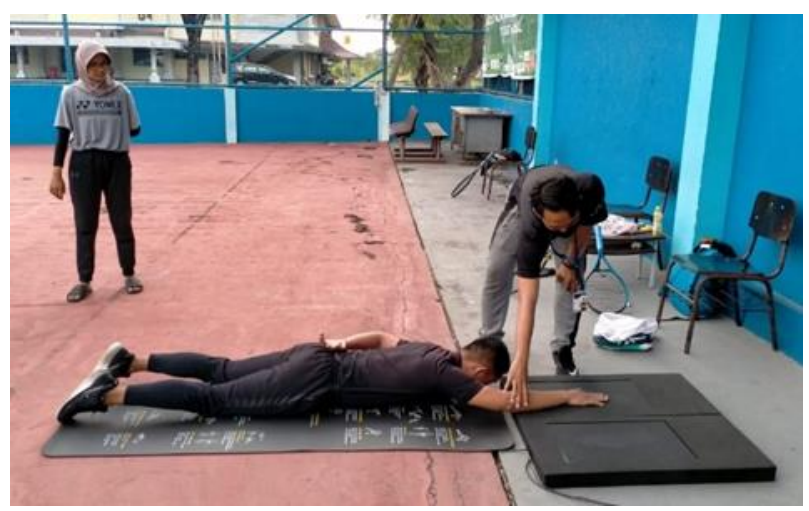

The upper extremity data were arm flexion (degree) at toss release also hip torso angle (degree), and arm flexion isometric bend (degree). The ball toss position data were ball release height $(\mathrm{cm})$, ball peak height $(\mathrm{cm})$, and ball impact height $(\mathrm{cm})$. Furthermore, the ball speeds were measured by Bushnell Velocity Speed Gun 101911, which was placed in the opposite direction of the serve (Figure 3).

Figure 1 Arm flexion isometric force measurement

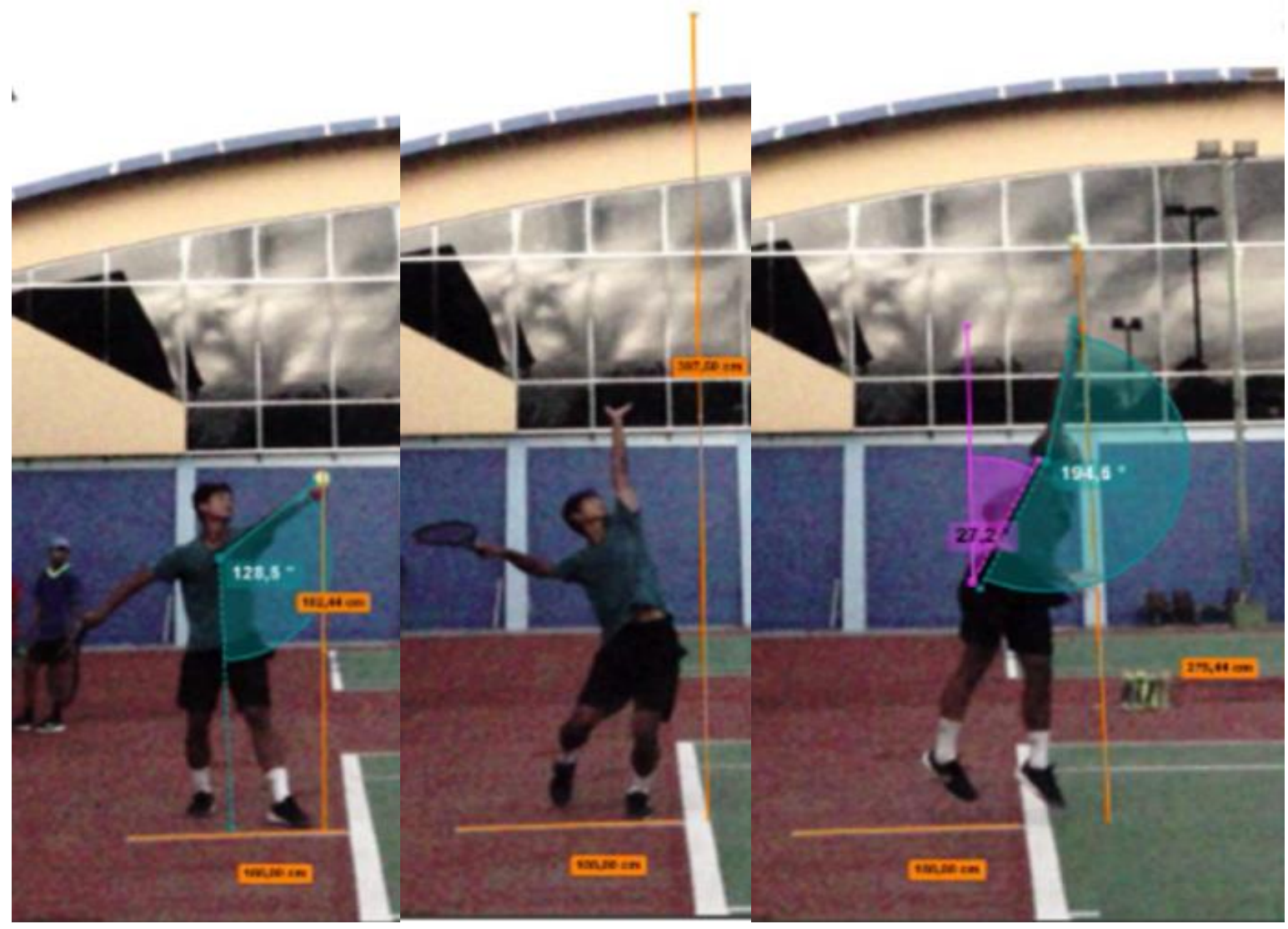

Ball Release Position

(B) Ball Peak Position

Ball Impact Position

Figure 2 Upper body movement and ball position measurement 


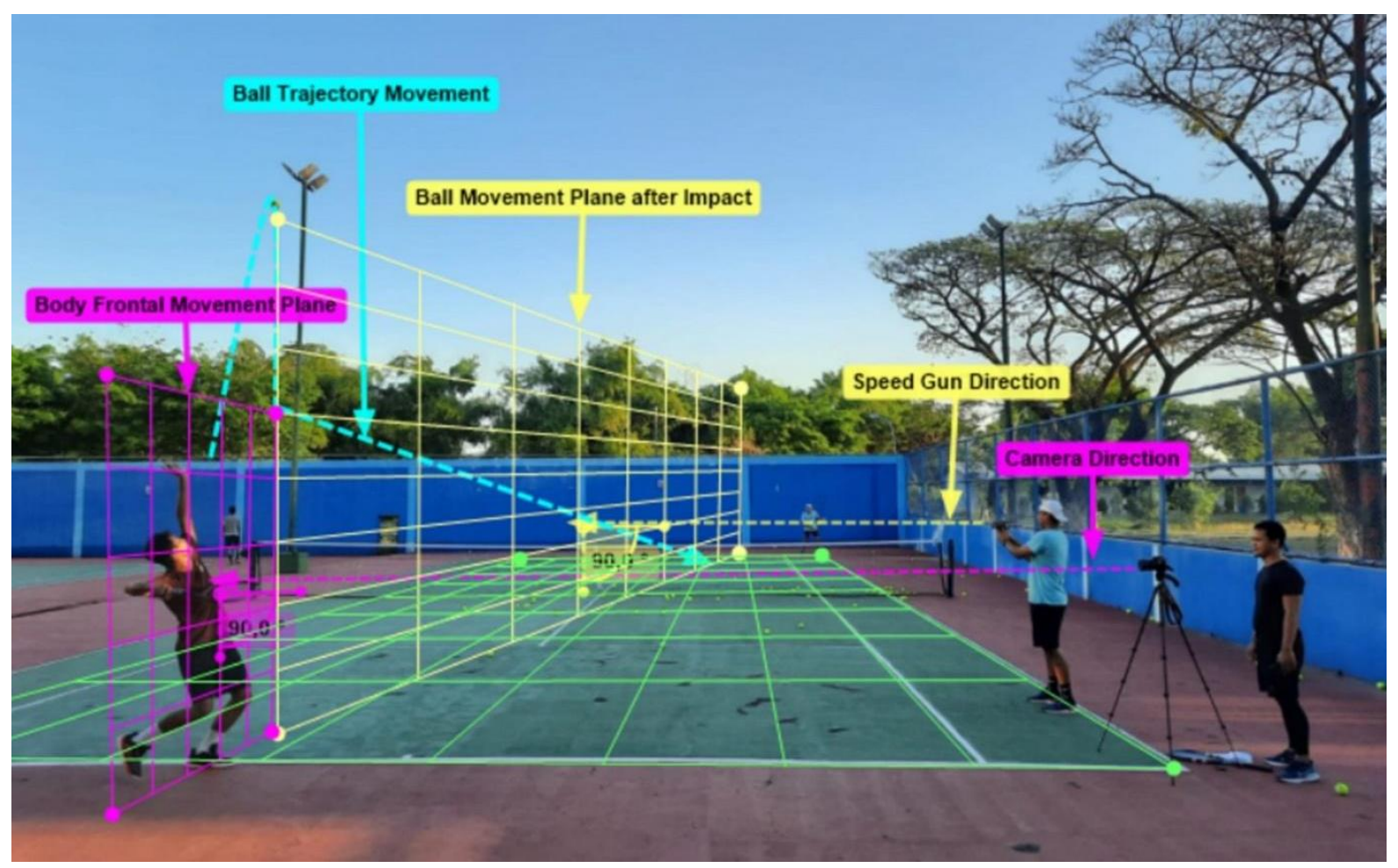

Figure 3 Schematic of field data collection from the sagittal plane

\subsection{Data Analysis}

Data were analyzed by using descriptive analysis and Kolmogorov-Smirnov normality test in SPSS statistical software. Furthermore, multiple linear regression was performed to find the correlation between variables. Data measurements were presented in mean and standard deviation $(\overline{\mathrm{x}} \pm \mathrm{SD})$. The significance level was set at $\alpha<0,05$, and all tests were two-tailed.

\section{RESULTS}

The descriptive data of research samples' profiles were found the average age of $20.78 \pm 5.04$ years old, with an average height of $171.67 \pm 11.07 \mathrm{~cm}$ and a weight of $63.22 \pm 14.63 \mathrm{~kg}$ (table 1)

Table 1. Research Samples Descriptive Analysis

\begin{tabular}{|l|l|c|c|}
\hline $\mathbf{n = 9}$ & Mean \pm SD & Min & Max \\
\hline Age & $20.78 \pm 5.044$ & 15 & 31 \\
\hline Height & $171.67 \pm 11.07$ & 153 & 183 \\
\hline
\end{tabular}

The kinetic data were analyzed by using the descriptive method. The mean of arm flexion isometric peak force was $131.22 \pm 41.27$ Newton, arm flexion isometric average force was $121.44 \pm 42.08$ Newton, and rate force development was $270.33 \pm 112.88$ milliseconds (table 2).
Table 2. Kinetic data descriptive analysis

\begin{tabular}{|l|l|c|c|}
\hline $\mathrm{n}=9$ & Mean \pm SD & Min & Max \\
\hline Peak Force $(\mathrm{N})$ & $131.22 \pm 41.27$ & 76 & 179 \\
\hline Average Force $(\mathrm{N})$ & $121.44 \pm 42.08$ & 74 & 116 \\
\hline RFD $(\mathrm{ms})$ & $270.33 \pm 112.88$ & 124 & 458 \\
\hline
\end{tabular}

The kinematic data were also analyzed by using the descriptive method. The mean arm flexion and ball height in ball release position were $120.39 \pm 14.65^{\circ}$ and 165.76 $\pm 25.39 \mathrm{~cm}$. The mean peak ball position was $337.08 \pm$ $23.92 \mathrm{~cm}$. At the ball impact position, the mean of the hip torso, arm flexion isometric, and ball height were 30.46 $\pm 15.42^{\circ}, 186.93 \pm 14.43^{\circ}$, and $258.77 \pm 26.51 \mathrm{~cm}$. The mean ball speed was $80.23 \pm 16.38 \mathrm{~km} / \mathrm{h}$ (Table 3 ).

Table 3. Kinematic Data Descriptive Analysis

\begin{tabular}{|c|c|c|c|}
\hline$n=9$ & Mean \pm SD & Min & Max \\
\hline \multicolumn{4}{|l|}{ Ball Release Position } \\
\hline Arm Flexion $\left({ }^{\circ}\right)$ & $120.39 \pm 14.65$ & 89.50 & 136.40 \\
\hline Ball Height $(\mathrm{cm})$ & $165.76 \pm 25.39$ & 120.10 & 211.11 \\
\hline \multicolumn{4}{|l|}{ Ball Peak Position } \\
\hline Ball Height $(\mathrm{cm})$ & $337.08 \pm 23.92$ & 306.41 & 379.50 \\
\hline \multicolumn{4}{|l|}{ Ball Impact Position } \\
\hline Hip Torso $\left({ }^{\circ}\right)$ & $30.46 \pm 15.42$ & 11.28 & 62.30 \\
\hline $\begin{array}{l}\text { Arm Flexion Isometric } \\
\left({ }^{\circ}\right)\end{array}$ & $186.93 \pm 14.43$ & 156.90 & 205.59 \\
\hline Ball Height $(\mathrm{cm})$ & $258.77 \pm 26.51$ & 219.84 & 296.42 \\
\hline Ball Speed (km/h) & $80.23 \pm 16.38$ & 59.21 & 103.19 \\
\hline
\end{tabular}

The normality test by Kolmogorov-Smirnov test, which was conducted to test the normality, showed that all of the data were in the standard distribution $(\alpha>0.05)$. Multiple linear regression indicated that the $\mathrm{R}$ score of kinetic was .638. Furthermore, the $\mathrm{R}$ score of kinematic was .974 (table 4). There was a significant correlation 
between ball height in peak position and impact position ( $\mathrm{R}$ Score > .666). Furthermore, kinematic had a significant correlation with ball speed (R Score > .666).

Table 4. Pearson correlation matrix toward ball speed

\begin{tabular}{|l|c|}
\hline & R Score \\
\hline Kinetic & .638 \\
\hline Peak Force $(\mathrm{N})$ & .601 \\
\hline Average Force $(\mathrm{N})$ & .573 \\
\hline RFD $(\mathrm{ms})$ & .124 \\
\hline Kinematic & $.974^{* *}$ \\
\hline Release - Arm Flexion $\left(^{\circ}\right)$ & .429 \\
\hline Release - Ball Height $(\mathrm{cm})$ & $.784^{*}$ \\
\hline Peak - Ball Height $(\mathrm{cm})$ & .291 \\
\hline Impact - Hip Torso $\left(^{\circ}\right)$ & .465 \\
\hline Impact - Arm Flexion Isometric $\left(^{\circ}\right)$ & .644 \\
\hline Impact - Ball Height $(\mathrm{cm})$ & $.766^{*}$ \\
\hline Notes: ${ }^{*}$ Sig $<.05 \&{ }^{* *}$ Sig $<.01$ & \\
\hline
\end{tabular}

\section{DISCUSSION}

Research has shown that the tennis flat serves very complex movements from kinetics and kinematics objects from the method until the results. Shoulder and elbow joint torques and forces at crucial phases of the service action were compared for players with a full and an abbreviated backswing and those with a more significant knee joint flexion compared to those with minimal knee flexion [8]. They identified arm flexion isometric force, upper extremity movement, and ball toss position towards ball speed in flat serve. The individual skill player showed a significant correlation in ball height in peak position and ball height in impact position. It means that the more ball height peak position, the more impact position. The player's anthropometry is very important to increase the chance impact position, but the excellent technique when flat serve is very dominant in the peak position. This research uses $2 \mathrm{D}$ motion analysis of flat serves about kinematics; the subsequent research could be using 3D motion capture analysis to compare the study.

\section{ACKNOWLEDGMENTS}

The research was funded by Universitas Negeri Surabaya in the Research Competition Scheme 2021.

\section{REFERENCES}

[1] A. Edel, Y. Song, T. Wiewelhove, and A. Ferrauti, "Activity profiles and physiological responses during match play in four popular racquet sports Belastungsund Beanspruchungsprofil von vier populären Rückschlagsportarten während eines Spiels," Ger. J. Exerc. Sport Res., vol. 49, no. 3, pp. 221-231, Sep. 2019, doi: 10.1007/s12662-019-00610-4.
[2] E. P. Roetert and M. S. Kovacs, Tennis Anatomy. Human Kinetics, 2011.

[3] A. Lees, "The evolution of racket sports science-a personal reflection," Ger. J. Exerc. Sports Res. 2019 493, vol. 49, no. 3, pp. 213-220, Jun. 2019, DOI: 10.1007/S12662-019-00604-2.

[4] S. C. Williams, J. Rive, and S. C. Williams, Skills \& Drills.

[5] C.-C. Chiang, Y.-H. Nien, J.-Y. Chiang, and T.-Y. Shiang, "Kinematic Analysis of Upper Extremity in Tennis Flat and Topspin Serve," J. Biomech., vol. 40, p. S196, Jan. 2007, DOI: 10.1016/S00219290(07)70192-6.

[6] M. C. Fu, T. S. Ellenbecker, P. A. Renstrom, G. S. Windler, and D. M. Dines, "Epidemiology of injuries in tennis players," Curr. Rev. Musculoskelet. Med., vol. 11, no. 1, pp. 1-5, 2018, DOI: 10.1007/s12178-018-9452-9.

[7] P. Malliou et al., "The Effect of Strength Training on Tennis Service," vol. 3, no. 1, pp. 31-40, 2011.

[8] B. Elliott, G. Fleisig, R. Nicholls, and R. Escamilla, "Technique effects on upper limb loading in the tennis serve," J. Sci. Med. Sport, vol. 6, no. 1, pp. 76-87, 2003, DOI: 10.1016/S1440-2440(03)800117.

[9] D. Eygendaal, F. T. G. Rahussen, and R. L. Diercks, "Biomechanics of the elbow joint in tennis players and relation to pathology," Br. J. Sports Med., vol. 41, no. 11, pp. 820-823, 2007, DOI: 10.1136/bjsm.2007.038307.

[10] D. Knudson and B. Elliott, "Biomechanics of Tennis Strokes," pp. 153-181, 2004, DOI: 10.1007/978-1-4419-8887-4_7.

[11] B. Elliott, "Biomechanics and tennis," Br. J. Sports Med., vol. 40, no. 5, pp. 392-396, 2006, DOI: 10.1136/bjsm.2005.023150.

[12] L. R. Ng and J. S. Kramer, "Shoulder rotator torques in female tennis and non-tennis players," J. Orthop. Sports Phys. Ther., vol. 13, no. 1, pp. 40-46, 1991, doi: 10.2519/jospt.1991.13.1.40.

[13] A. Bonnefoy-Mazure, J. Slawinski, A. Riquet, J. M. Lévèque, C. Miller, and L. Chèze, "Rotation sequence is an important factor in shoulder kinematics. Application to the elite players' flat serves," J. Biomech., vol. 43, no. 10, pp. 2022 2025, Jul. 2010, DOI: 10.1016/J.JBIOMECH.2010.03.028.

[14] H. I. M. F. L. Pas et al., "Effectiveness of an ehealth tennis-specific injury prevention program: Randomised controlled trial in adult recreational 
tennis players," Br. J. Sports Med., vol. 54, no. 17, pp. 1036-1041, 2020, DOI: 10.1136/by sports2019-101142.

[15] A. L. Sheets, G. D. Abrams, S. Corazza, M. R. Safran, and T. P. Andriacchi, "Kinematics Differences Between the Flat, Kick, and Slice Serves Measured Using a Markerless Motion Capture Method," Ann. Biomed. Eng. 2011 3912, vol. 39, no. 12, pp. 3011-3020, Oct. 2011, DOI: 10.1007/S10439-011-0418-Y.

[16] K. Kalo, L. Vogt, J. Sieland, W. Banzer, and D. Niederer, "Injury and training history are associated with glenohumeral internal rotation deficit in youth tennis athletes," BMC Musculoskelet. Disord. 2020 211, vol. 21, no. 1, pp. 1-7, Aug. 2020, DOI: 10.1186/S12891-020-03571-0. 